\title{
Waste heat: the dominating root cause of current global warming
}

\author{
Qinghan Bian*
}

\begin{abstract}
Background: Pursuing GHG reductions by means of all resources and efforts has turned out no result to stop or even slow the global warming: the globe still gets warmer and warmer, especially in the recent years, at record-breaking rate almost each single year. Additionally, no definitive relationship has been found between the warming and the atmospheric GHG concentration. The link between them even in IPCC's report lacks support and is unconvincing. All these imply that something else is responsible for the warming. On the other hand, huge amount of residual heat or waste heat from human activities has been poured into the climate system but has not been considered seriously in the context of global warming or climate change.

Results: This article features deploying the basic principles of thermodynamics and applying a new model, Equivalent Climate Change Model, to analyse the currently available data on world energy consumption between 1965 and 2017, and to study the relation between the global warming and the waste heat entered the climate system. The results show that the temperature changes in air, oceans and land are definitively correlated to the respective heat allocated from the waste heat stream based on their specific heat capacities, with high certainty and reliability. The observed anomalies in air fall within a range of simulations at an equivalent climate change surface air boundary layer depth between 50 and $100 \mathrm{~m}(60 \sim 100 \mathrm{~m}$ in recent decades due to more establishments of high-rising heat discharging sources); the anomalies in oceans fall within a range of simulations at an equivalent climate change waters surface boundary layer depth between 0.10 and $0.20 \mathrm{~m}$ (0.125 0.20 $\mathrm{m}$ in recent decades); and the anomalies in land fall within a range of simulations at an equivalent climate change land surface boundary layer depth between 0.05 and $0.10 \mathrm{~m}$ (0.06 0.10 $\mathrm{m}$ in recent decades). The simulation results at the air layer depth of $70 \mathrm{~m}$ are almost the same as NASA's Lowess smoothing trend. Forecast of future global warming based on this model under the scenario of business as usual indicates that the possible air temperature risings will be in the range of $0.68 \sim 1.13^{\circ} \mathrm{C}$ in 2030 and $0.73 \sim 1.22^{\circ} \mathrm{C}$ in 2040 ; the possible sea temperature risings will be in the range of $0.61 \sim 0.98^{\circ} \mathrm{C}$ in $2030,0.66 \sim 1.05^{\circ} \mathrm{C}$ in 2040; and the possible land temperature risings will be in the range of $1.02 \sim 1.71{ }^{\circ} \mathrm{C}$ in $2030,1.10 \sim 1.84^{\circ} \mathrm{C}$ in 2040 . However, if the energy conversion efficiency increased by $10 \%$ by 2030 and another $10 \%$ by 2040 , then the possible air temperature risings would be in the range of $0.54 \sim 0.90^{\circ} \mathrm{C}$ in 2030 and $0.44 \sim 0.73^{\circ} \mathrm{C}$ in 2040 ; the possible sea temperature risings would be in the range of $0.49 \sim 0.78^{\circ} \mathrm{C}$ in 2030 , and $0.40 \sim 0.64{ }^{\circ} \mathrm{C}$ in 2040 ; and the possible land temperature risings would be in the range of $0.81 \sim 1.36^{\circ} \mathrm{C}$ in 2030 and $0.66 \sim 1.11^{\circ} \mathrm{C}$ in 2040 . The observed global average air temperature changes and the Lowess Smoothing values in 2018 and 2019 fall within the range set by the air layer depth between 60 and $100 \mathrm{~m}$, are consistent with the forecast under the scenario of business as usual, further confirms the reliability of this approach.
\end{abstract}

Conclusions: Greenhouse gases are not the culprit of the current global warming, instead, huge amount of residual heat or waste heat discharged into the environment from human activities has dominated the warming (beside

*Correspondence: bianqinghan@hotmail.com

Victoria, BC V8P 5B6, Canada in this article are included in the article's Creative Commons licence, unless indicated otherwise in a credit line to the material. If material is not included in the article's Creative Commons licence and your intended use is not permitted by statutory regulation or exceeds the permitted use, you will need to obtain permission directly from the copyright holder. To view a copy of this licence, visit http://creativeco mmons.org/licenses/by/4.0/. 
of solar irradiance and volcano eruptions). Pursuing GHG reductions is bound to be ineffective in preventing the globe from further warming but increases unnecessary burdens. Switching to $100 \%$ of surface renewable energies is the ideal solution to completely solve further warming problem. However, geotherm does cause global warming although it is a type of renewable energy. Increasing energy's conversion efficiency can effectively help slow down the warming, it requires vast investment and will embrace breakthroughs in technologies. Changing human's behavior individually and socially and retrofitting can decrease the energy consumption and the amount of heat entering the environment and thus help mitigate climate change and its impact in the most cost-effective way. Unlike the General Circulation Models that can only simulate the past air temperature changes with greater uncertainty, the Equivalent Climate Change Model can not only trace the past temperature changes in air, oceans and land, but also can predict the future changes in them, respectively, with high certainty and reliability.

Keywords: Climate change, Equivalent climate change model, Energy conversion efficiency, Forecast, Global warming, Residual heat, Waste heat

\section{Background}

\section{Greenhouse gases don't cause the current global warming/} climate change

Global warming drives climate change. It has been an urgent, sustainability threatening issue. The globe gets warmer and warmer, especially in recent years at recordbreaking rates year after year, and no slow-down sign has been seen yet although huge efforts and resources have been deployed. This basically indicates that the current approach to fighting climate change through reducing greenhouse gas (GHG) emissions is ineffective and inefficient.

Three things might have influenced the climate. They are tectonic changes, solar irradiance variance and human activities. Regarding solar irradiance, it is believed that its variance can only induce a temperature change up to a level of $0.1{ }^{\circ} \mathrm{C}$ during an 11-year solar cycle as mentioned in (Bian 2019), though arguments exist. Consequently, it is unlikely that the variance of solar activity has caused climate change to the currently observed level.

It is reported that the comparison between prehistorical global warming and atmospheric GHG (i.e. $\mathrm{CO}_{2}$ and $\mathrm{CH}_{4}$ ) concentrations found their similarity in the change trend, and thus it is concluded that GHGs caused the prehistorical warming (Skeptical Science 2020) based on the concept of Greenhouse Effect. It is worth to note that in the far ancient time fierce tectonic changes and volcano eruptions blew out vast amount of geotherm with associated gases of $\mathrm{CO}_{2}$ and $\mathrm{CH}_{4}$. The geotherm broke the earth's energy budget balance (Bian 2019), warmed the air and caused the warming, while the GHGs just coincidently experienced the change. The concurrent participation of the geotherm and GHGs in the ancient climate change may explain why the prehistoric climate change has the similar trend to the then-atmospheric GHGs. In modern time such fierce tectonic changes (except for earthquakes) have not occurred, but volcano eruptions do make contributions to the current climate change, to some extent, as discussed in (Bian 2019).

It's been widely perceived that Greenhouse Effect dominates the current warming based on the presumption that GHGs form a blanket over the earth. The blanket traps the infrared radiations from the earth surface from escaping into the space, and then reflects the radiation back to the earth as heat, warming it up. However, it's very difficult to imagine how these spatially randomly distributed trace gases (only about $0.04 \%$ of the air volume) can form a blanket in the atmosphere over the earth, because $99.96 \%$ of the air volume is occupied by other molecules, leaving almost all the atmosphere "free of GHGs", forming an open gateway for the radiations to travel to the space. Therefore, GHG's effect has been exaggerated.

Additionally, do GHGs really have so strong forcing and heat-trapping capacities in such low level of concentrations? If so, then it would be very possible to develop new energy storage sources by using their concentrates to trap/absorb heat, since commercial natural gas and dry ice are readily available, and even collecting them from emission sources is not difficult, but it is not the case yet. Unlike specific heat capacity-an attribute of a material, the forcing and global warming potentials of GHGs are just given indices calculated based on the warming level and the gas' concentrations, not the material's intrinsic properties.

On the other hand, no definitive relation has been found between the current global warming and the GHG concentration though large number of climate change models have been developed. This can be seen from IPCC's assembly of many simulations from selected models. Their mean of these simulations is used to compare with the observed temperature anomalies, but big gaps still exist (Fig. 1) (Flato 2013). Therefore, claiming GHGs have caused the current global warming and climate change lacks solid support and is unconvincing, because, 
a Observed and CMIP5 slmulated global mean surface alr temperature

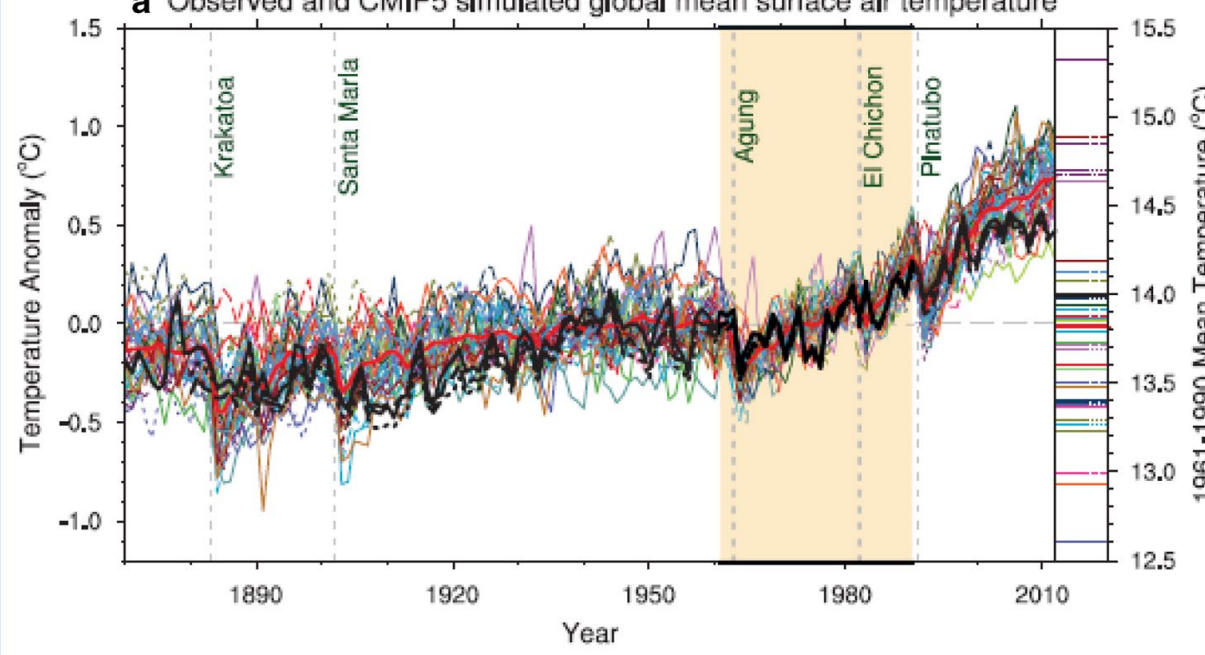

b Observed and EMICs simulated global mean surface air temperature

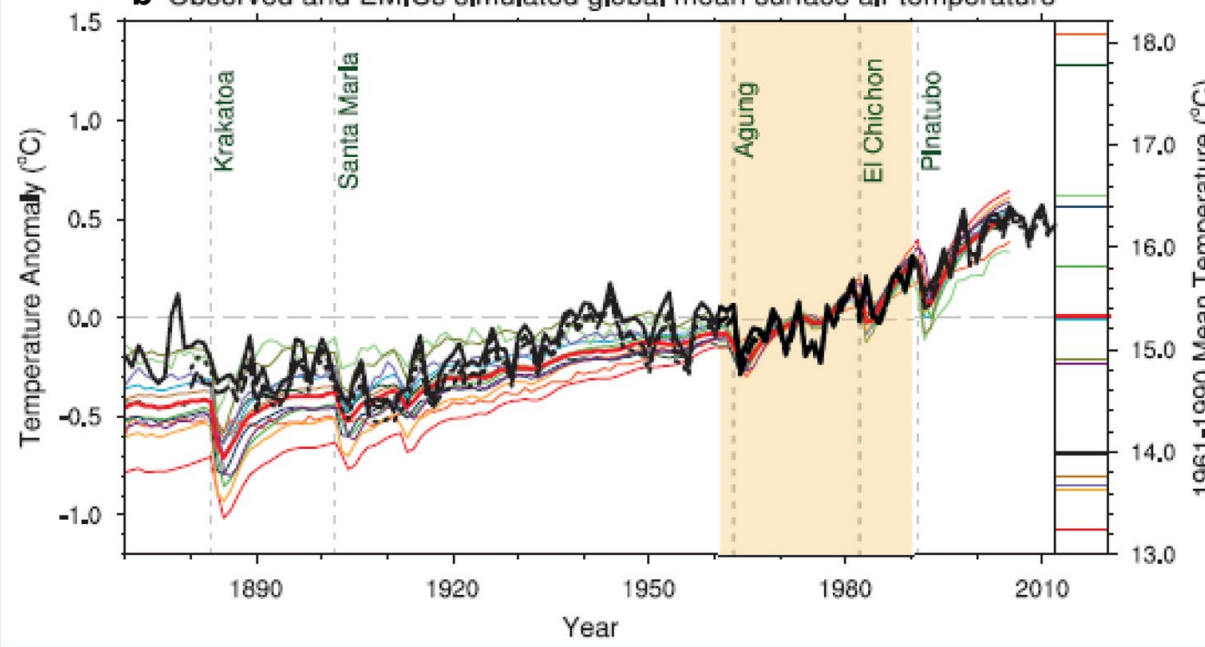

- Matenuta

- - - GITEN

CNP5 mavi

- Acotissi,

- Bccossat:

Buses.

- cesmipac

. . CEgMVICAMS

chocon

- conccian

CNAMGas

cantemsisen

no-son

- G GDL-I5mas

- . - gFolesnan

- chintirit

- - cestom

- - - - COEEEZA

- - CEसE-

- - Hablar

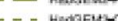

- Hindemses

- Fackats

- - Vtidomater

- - - pal-cuese

- Macs

- - 4hoctsu

- . - Mocesus

- — wrats

- Mikgacis

_ NOEEM -A

- - Noregume

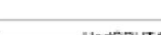

- HaDCRIT

- - - COSTEM

-.-- Must

- EMC mǘ

- CLMMERE

- CLMMER

DOESS

- GEME

VISME

P RAS CU

LONECW

— MESMO

— Udo

Fig. 1 Observed and simulated time series of the anomalies in annual and global mean surface temperature. All anomalies are differences from the 1961-1990 time-mean of each individual time series. a Single simulations for CMIP5 models (thin lines); b Single simulations from available EMIC simulations (thin lines), from Eby et al. (2013); multi-model mean (thick red line); different observations (thick black lines) (Fig. 9.8 in the original source) (Flato 2013)

as well known, a definitive relation must exist between any two correlated things. This may be the reason why IPCC cautiously declares "climate change is real and human activities are the main cause" (United Nations et al. 2020), without explicitly linking the warming to GHGs. Unfortunately, almost all the efforts and resources have been focused on GHG emissions and their reductions worldwide so far, while the energy flow and the associated waste heat from human activities have been overlooked. Furthermore, by the current GHG-based theory, it is neither possible to track the past temperature changes nor to predict the future temperature changes in the surfaces of both oceans and land.

Global warming is a thermodynamic problem, it starts from the ground level. Studies should focus on the phenomena in the surface level of air, oceans and land since they regulate and dominate concurrently the ground level temperature that suits for human's living. The temperature changes in surface air, oceans surface and land surface are "coordinated" by these components through allocating heat entered the climate system based on their specific heat capacities (Bian 2019). 
Waste heat-huge amount entering the environment According to the Law of Conservation of Energy, energy cannot disappear nor be destroyed after use, it can only be converted from one form to another. Beside of the energy converted to useful work or chemical energy stored in new products, there is also residual heat or waste heat from energy application processes that has been discharged into the climate system, for example (Bian 2019):

- In our daily life, taking showers, drying laundry (except for sun dry) directly pour heat into the environment, while air conditioning directly heats the air;

- In transportation, only about $12 \sim 41 \%$ of the fuel consumed is used to do the "useful work", while all the rest is discharged into the environment in the form of heat;

- In industries, drying moisture-containing materials discharges all consumed energy directly into the environment in the form of heat along with the evaporated water and the hot materials;

- During lime production with a typical rotary kiln process, about $43.4 \%$ of the input energy is dispersed into the environment as heat. For other types of kilns, the waste heat may be more;

- In cement production, about $55.5 \sim 68.6 \%$ of the input energy is lost in the form of heat, through exhaust gas, kiln shell, hot product etc.;

- As for electricity generation, only about $38 \%$ of the primary energy is converted to electricity in a modern plant, with the rest wasted to the environment in the form of heat.

In general, about $100 \%$ of energy consumed in residential and commercial, $75 \%$ in transportation and $70 \%$ in industrial applications are discharged into the environment as heat globally (Bian 2019).

Additionally, there is countless flaring at oil and gas development/processing sites, petroleum refineries and petrochemical plants, coal mining and processing facilities, waste management and landfill locations etc., which heats the air and sends heat to the environment continuously $(24 / 7 / 365)$ worldwide.

It is further estimated that the current global energy's total effective conversion efficiency (GETECE, or simply energy conversion efficiency) is only about $20 \%$, i.e. merely about $20 \%$ of the consumed global energy is converted to new products and useful work, while the rest $80 \%$ enters the climate system as residual heat or waste heat, breaks the earth's energy budget balance (Bian 2019). It is this huge amount of heat that has caused and is continuing to cause the global warming (Bian 2019). Among the $80 \%$, industry contributes about $44 \%$, residential and commercial $36 \%$ and transportation $20 \%$. Therefore, personal contribution is not small globally and cannot be ignored. Furthermore, this heat, after entering the environment (i.e. land-ocean-air climate system), is redistributed among the air, land and oceans based on their specific heat capacities (Bian 2019).

Some studies have discussed the effect of waste heat (Flanner 2009), or anthropogenic thermal emission (Murray and Heggie 2016). Flanner (2009) indicated that almost all energy used for human purposes is dissipated as heat within Earth's land-atmosphere system, while the heat from non-renewable sources constitutes a climate forcing term, with a global average value of $0.028 \mathrm{~W} /$ $\mathrm{m}^{2}$. The latter is compared to GHG's forcing of $2.9 \mathrm{~W} /$ $\mathrm{m}^{2}$ (IPCC Fourth Assessment Report: Climate 2007) and, thus it is concluded that waste heat from human activities is only about $1 \%$ of the GHGs' effect (Skeptical Science 2020). However, estimating waste heat's forcing at the top of the atmosphere itself neglects its absorption by air, exaggerated its effect, if that is appropriate. On the other hand, about $30 \%$ of industrial energy converted to new products in the form of chemical energy and $25 \%$ of fuel converted to useful work in transportation (Bian 2019) undercut Flanner's claim. Thus, Flanner's insistence of "almost all energy... is dissipated as heat within Earth's land-atmosphere system" seems to be overestimated and inaccurate. Flanner (Flanner 2009) pioneeringly tried to incorporate waste heat into GHG-based climate change modelling, but did not examine how the heat directly warmed the air from the perspective of thermodynamics.

Murray and Heggie (2016) compared anthropogenic thermal emission and temperature changes at national level for Japan and Great Britain, found that the energy consumption (serving as the proxy of thermal emission) and the temperature above background change have strong correlation, in contrast with the weaker correlation by CMIP5 model. Although being very interesting, Murray and Heggie (2016) obviously overestimated the thermal output and thus provided less accuracy; did not explore further how the thermal emission affected the temperature change. In addition, because of only considering two countries, the results is less representative in the context of a global scale.

Nevertheless, all these suggest that waste heat or residual heat from human activities contribute to the global warming and climate change, but how much its contribution is and what is the exact relation between them need to be investigated on a global scale.

\section{Method}

Studying global warming and climate change must look at the temperature changes in air, sea and land at the same time. This project features the simultaneous investigation of temperature changes in surface air, sea surface 
and land surface on global scale by thermodynamics, through allocating the waste heat stream to these three components (i.e. air, oceans and land) according to their specific heat capacities, and by using a new global model, i.e. Equivalent Climate Change Model (Bian 2019). The model consists of an equivalent climate change surface air boundary layer, an equivalent climate change waters surface boundary layer and an equivalent climate change land surface boundary layer. By following the procedures described in (Bian 2019), currently available data on world energy consumption is used to determine heat energy entered the climate system in order to simulate the past (global average) temperature changes in these components, and their future temperature changes are also forecast based on predicted energy consumption.

It is assumed that part of the waste heat has been consumed to melt ice and raise its temperature to sea water's temperature before raising the temperatures in air, oceans and land, as shown below (Bian 2019):

$$
\Delta H_{i w}=Q_{i} \cdot L_{p i}+Q_{i} \cdot C_{p w} \cdot\left(T_{s w}-T_{i w}\right)
$$

The temperature changes in air, oceans and land are the unique functions of the respective heat entered them (Bian 2019). The relations between temperature changes and the heat "input" are clear and determinative as shown below:

The relationship between surface air temperature changes and the allocated waste heat,

$$
\Delta t_{a}=\frac{3 \Delta H_{a}}{4 \pi\left[\left(R_{o}+h\right)^{3}-R_{o}^{3}\right] \cdot \rho_{a} \cdot C_{p a}}
$$

The relationship between sea surface temperature changes and the allocated waste heat,

$$
\Delta t_{w}=\frac{\Delta H_{w}}{S_{w} \cdot D_{w} \cdot \rho_{w} \cdot C_{p w}}
$$

The relationship between land surface temperature changes and the allocated waste heat,

$$
\Delta t_{L}=\frac{\Delta H_{L}}{S_{L} \cdot D_{L} \cdot \rho_{L} \cdot C_{p L}}
$$

Where,

$\mathrm{R}_{0} \quad$ Earth's radius, $6371 \mathrm{~km}$

$\mathrm{h}$ The depth (or altitude) of the air layer measured from the earth surface

$\mathrm{S}_{\mathrm{w}} \quad$ Seawater surface area, 361,800,000 $\mathrm{km}^{2}$

$\mathrm{D}_{\mathrm{w}} \quad$ The depth of the sea waters' layer

$\rho_{\mathrm{a}} \quad$ Air density under normal pressure

$\mathrm{C}_{\mathrm{pa}} \quad$ Air specific heat capacity under constant pressure, or the isobaric heat capacity
$\Delta \mathrm{H}_{\mathrm{a}} \quad$ The heat entered air layer that incurs the temperature change $\Delta \mathrm{t}_{\mathrm{a}}$

$\Delta \mathrm{t}_{\mathrm{a}} \quad$ The temperature change in the air layer after experiencing heat change $\Delta \mathrm{H}_{\mathrm{a}}$

$\rho_{\mathrm{w}} \quad$ The waters', mainly seawaters' density

$\Delta \mathrm{H}_{\mathrm{w}} \quad$ The heat entered seawaters layer that incurs the temperature change $\Delta \mathrm{t}_{\mathrm{w}}$

$\Delta \mathrm{t}_{\mathrm{w}} \quad$ The temperature change in the seawaters layer after experiencing heat change $\Delta \mathrm{H}_{\mathrm{w}}$

$\mathrm{C}_{\mathrm{pw}}$ Seawaters specific heat capacity under normal pressure

$\rho_{\mathrm{L}} \quad$ The land (soil) density

$\Delta \mathrm{H}_{\mathrm{L}} \quad$ The heat entered land layer that incurs the temperature change $\Delta t_{L}$

$\Delta \mathrm{t}_{\mathrm{L}} \quad$ The temperature change in the land layer after experiencing heat change $\Delta \mathrm{H}_{\mathrm{L}}$

$\mathrm{C}_{\mathrm{pL}} \quad$ Land (soil) specific heat capacity under normal pressure

$\mathrm{S}_{\mathrm{L}} \quad$ Land area on the earth surface, 148,264,472 $\mathrm{km}^{2}$ based on the Earth's total surface area $\left(510,064,472 \mathrm{~km}^{2}\right)$ and the total oceans' surface area $\left(361,800,000 \mathrm{~km}^{2}\right)$

$\mathrm{D}_{\mathrm{L}} \quad$ Depth of land layer

The simulation results calculated at different boundary layer depths are compared to those observed temperature anomalies, and future predictions are conducted too.

\section{Results and discussions \\ Past simulations}

It is revealed that (Bian 2019) an equivalent climate change surface air boundary layer with a depth between 50 and $100 \mathrm{~m}$ (also referred to as the depth's lower and upper layer limits), an equivalent climate change waters surface boundary layer with a depth between 0.1 and $0.2 \mathrm{~m}$, and an equivalent climate change land surface boundary layer with a depth between 0.05 and $0.1 \mathrm{~m}$ can well characterize their respective temperature changes due to the heat entered air (Fig. 2), oceans and land from human activities. The simulations at these depths are well consistent with the observed temperature anomalies in these three components (Bian 2019). These depths are referred to as equivalent climate change boundary layers' depths.

Additionally, in recent decades the lower limit of air boundary layer depth of $50 \mathrm{~m}$ may have overestimated the warming due to more establishments of high-rising heat discharging sources, while an extended lower-depth of $60 \mathrm{~m}$ produces more reasonable results. Even so, a 70-m depth of the air layer is still representative for the simulations and its results are almost the same as the NASA's Lowess Smoothing trend as the small insert in 


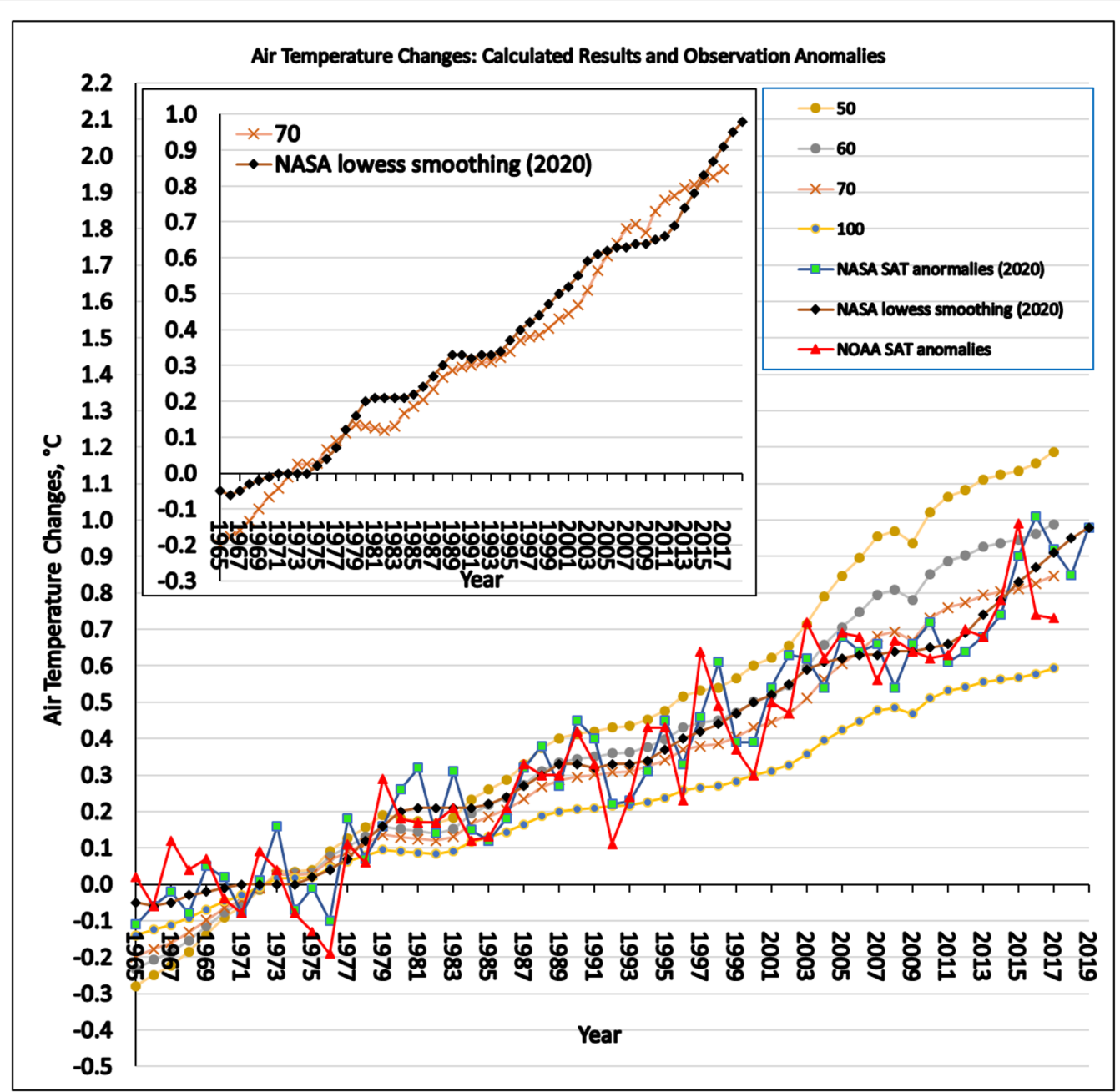

Fig. 2 Simulation of global surface air temperature changes in an air boundary layer at different depths between 1965 and 2017, and NASA, NOAA's surface air temperature anomalies (SAT), NASA's Lowess Smoothing trend

Fig. 2 shows (note that NASA's Lowess Smoothing dataset in Bian (2019) was taken from NASA's website in later 2018, while the dataset used here was taken from NASA's website in April 2020), which is the most matching results to NASA's values through a single simulation found so far among various simulations, providing the evidence that waste heat influences the air temperature.

The similar trends are also seen in the oceans and land boundary layers. As augmented amount of heat flux entered them, the minimal heat transfer distances, i.e. the lower limits of depths of the oceans and land boundary layers shifted to $0.125 \mathrm{~m}$ from $0.10 \mathrm{~m}$, and $0.06 \mathrm{~m}$ from $0.05 \mathrm{~m}$ in recent decades, respectively.

Compared to those approaches using General Circulation Models (GCMs) and atmospheric GHG concentration as summarized in Fig. 1 (Flato 2013) above, by which their individual simulation results of past air temperature changes cannot match the observed anomalies, and by which past temperature changes in oceans and land cannot be simulated, this newly proposed modelling described here and in Bian (2019), based on the allocated waste heat flux, can not only match the air temperature anomalies (Figs. 2, 3, 4) but

(See figure on next page.)

Fig. 3 Calculated past temperature changes at the lower and upper depth limits of equivalent climate change surface air boundary layer (top), equivalent climate change waters surface boundary layer (middle), and equivalent climate change land surface boundary layer (bottom), and the temperature change forecast as well as their observed temperature anomalies under scenario SF1 

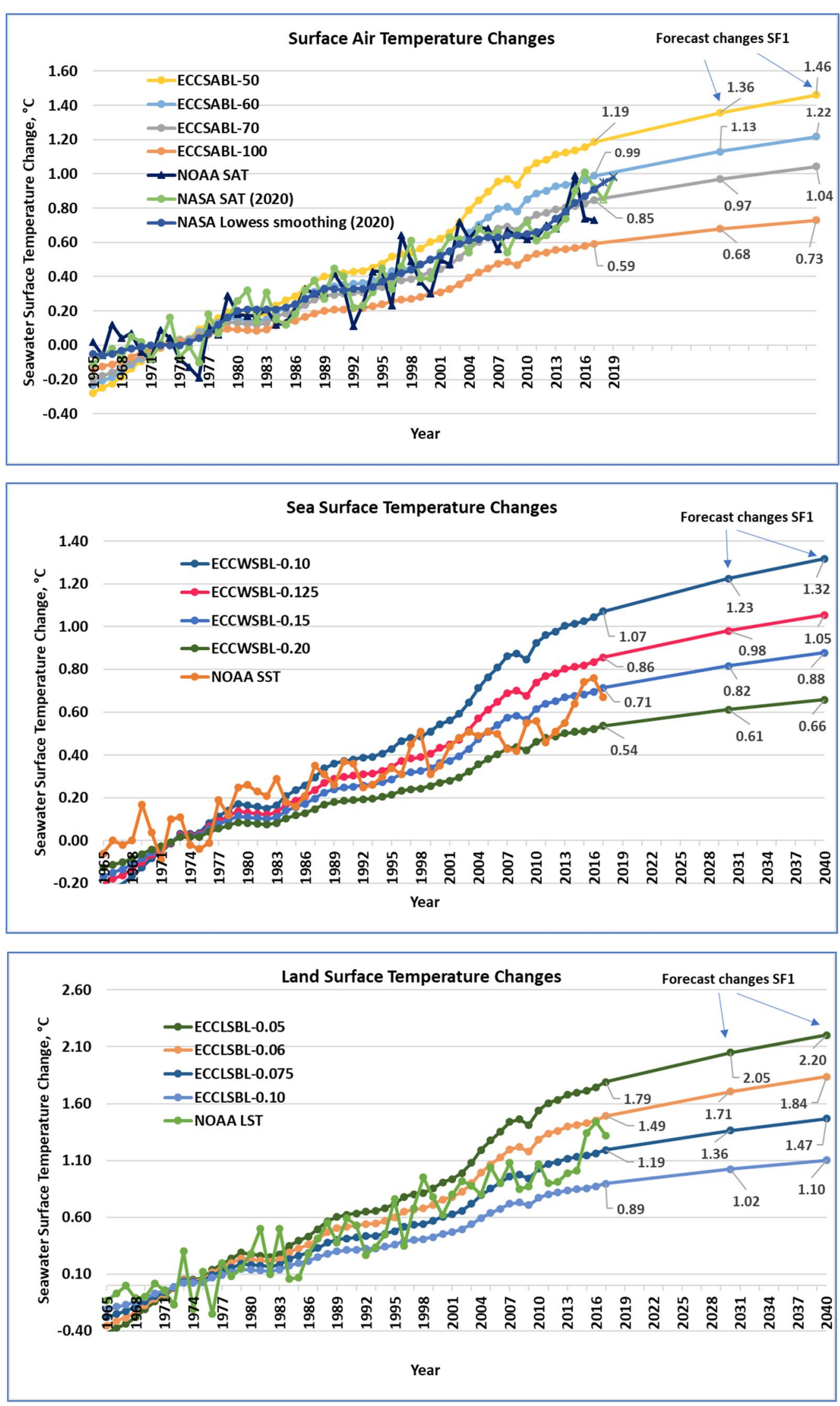
(See figure on next page.)

Fig. 4 Calculated past temperature changes at the lower and upper depth limits of equivalent climate change surface air boundary layer (top), equivalent climate change waters surface boundary layer (middle), and equivalent climate change land surface boundary layer (bottom), and the temperature change forecast as well as their observed temperature anomalies under scenario SF2

also match those in land and oceans (Figs. 3, 4), all with high certainty and reliability.

All these clearly suggest that the current global warming is a direct result of the huge amount of waste heat discharged into the climate system from human activities, implying that the residual heat or waste heat is the main contributor to the current global warming or climate change.

\section{Future warming forecast}

Figures 3, 4 show the future temperature forecasts in air, oceans and land by following the procedures described in (Bian 2019) according to BP's prediction of global energy consumption in 2030 and 2040 (BP Energy Outlook 2019), where the simulated past temperature changes at the lower and upper depth limits of the respective boundary layers are also exhibited together with the observed temperature anomalies. It is assumed that, as for the simulation of past temperature changes, ice melting remains at the current rate constantly for the calculations. The results suggest that using this model and the appropriate boundary layer depths can estimate the ranges of future global temperature changes with high certainty and reliability, while the temperature changes calculated at the depths of $70 \mathrm{~m}$ for air, $0.15 \mathrm{~m}$ for oceans and $0.075 \mathrm{~m}$ for land are considered representative of the future warmings.

Future temperature changes in 2030 and 2040 are predicted under two different scenarios: (1) business as usual (SF1, Fig. 3) and (2) elevated GETECEs, i.e. the energy conversion efficiency increased by $10 \%$ at 2030 and 2040 , respectively (SF2, Fig. 4).

Under scenario SF1, the forecast of future warming will be in the following ranges $\left({ }^{\circ} \mathrm{C}\right)$ : in 2030 air $0.68 \sim 1.13$, oceans $0.61 \sim 0.98$ and land $1.02 \sim 1.71$; in 2040 air $0.73 \sim 1.22$, oceans $0.66 \sim 1.05$ and land $1.10 \sim 1.84$ at the layer depth between 60 and $100 \mathrm{~m}$ for air, 0.125 and $0.2 \mathrm{~m}$ for oceans, and 0.06 and $0.1 \mathrm{~m}$ for land, as shown in Fig. 3, where their representative temperature change forecast are also indicated.

It is important to note that the respective global average air temperatures, 0.85 and $0.98^{\circ} \mathrm{C}$ in 2018 and 2019 , and their respective Lowess Smoothing values, 0.95 and $0.98{ }^{\circ} \mathrm{C}$ (National Aeronautics and Space Administration 2020), fall within the forecast range set by the air layer depth between 60 and $100 \mathrm{~m}$ under the business as usual scenario as can be seen in Fig. 3. This further confirms that this approach is reliable, and the forecast is consistent with the expectation under the scenario of business as usual.

Under the scenario SF2, the corresponding temperature changes would be in the following ranges $\left({ }^{\circ} \mathrm{C}\right)$ : in 2030 air $0.54 \sim 0.90$, oceans $0.49 \sim 0.78$ and land $0.81 \sim 1$. 36; in 2040 air $0.44 \sim 0.73$, oceans $0.40 \sim 0.64$ and land $0.66 \sim 1.11$ at the layer depth between 60 and $100 \mathrm{~m}$ for air, 0.125 and $0.2 \mathrm{~m}$ for oceans, and 0.06 and $0.1 \mathrm{~m}$ for land, as shown in Fig. 4, where their representative temperature change forecast are also indicated.

The existing approaches for studying climate change have great uncertainty, therefore, four Representative Concentration Pathways (RCPs) were proposed. Compared to those forecasts under various scenarios, for example, the global mean surface (air) temperature change for the period 2016 2035 relative to 1986 2005 will likely be in the range of $0.3 \sim 0.7{ }^{\circ} \mathrm{C}$ (medium confidence, similar for the four RCPs), for the period $2046 \sim 2065$ in the range of $0.4 \sim 2.6{ }^{\circ} \mathrm{C}$ for the four RCPs (IPCC 2014), the forecasts by this study under the scenario of business as usual are very reasonable and of greater confidence and certainty, plus the trend is unique and only relies on the projected global energy consumption and dissipated waste heat.

\section{Conclusion and strategies}

We need to realize the reality that huge amount of residual/waste heat from human activities has entered and continues to enter the climate system that incurs the current global warming. The amount of waste heat is about $80 \%$ of the consumed global energy, among which industry contributes about $44 \%$, commercial and residential about $36 \%$ and transportation $20 \%$. Everyone contributes to it unconsciously and unwillingly. GHGs are not culpable for the current global warming.

By means of the Equivalent Climate Change Model and allocating the waste heat stream to the climate system's three components i.e. air, land and oceans based on their specific heat capacity, it is possible to simulate their past temperature changes and predict future warmings with high certainty and reliability. The temperature changes in surface air layer with a depth between 50 (recently 60) and $100 \mathrm{~m}$ are consistent with the observed global air temperature anomalies; temperature changes in sea surface layer with a depth between 0.10 (recently 0.125 ) and $0.20 \mathrm{~m}$ are consistent with the observed sea temperature 

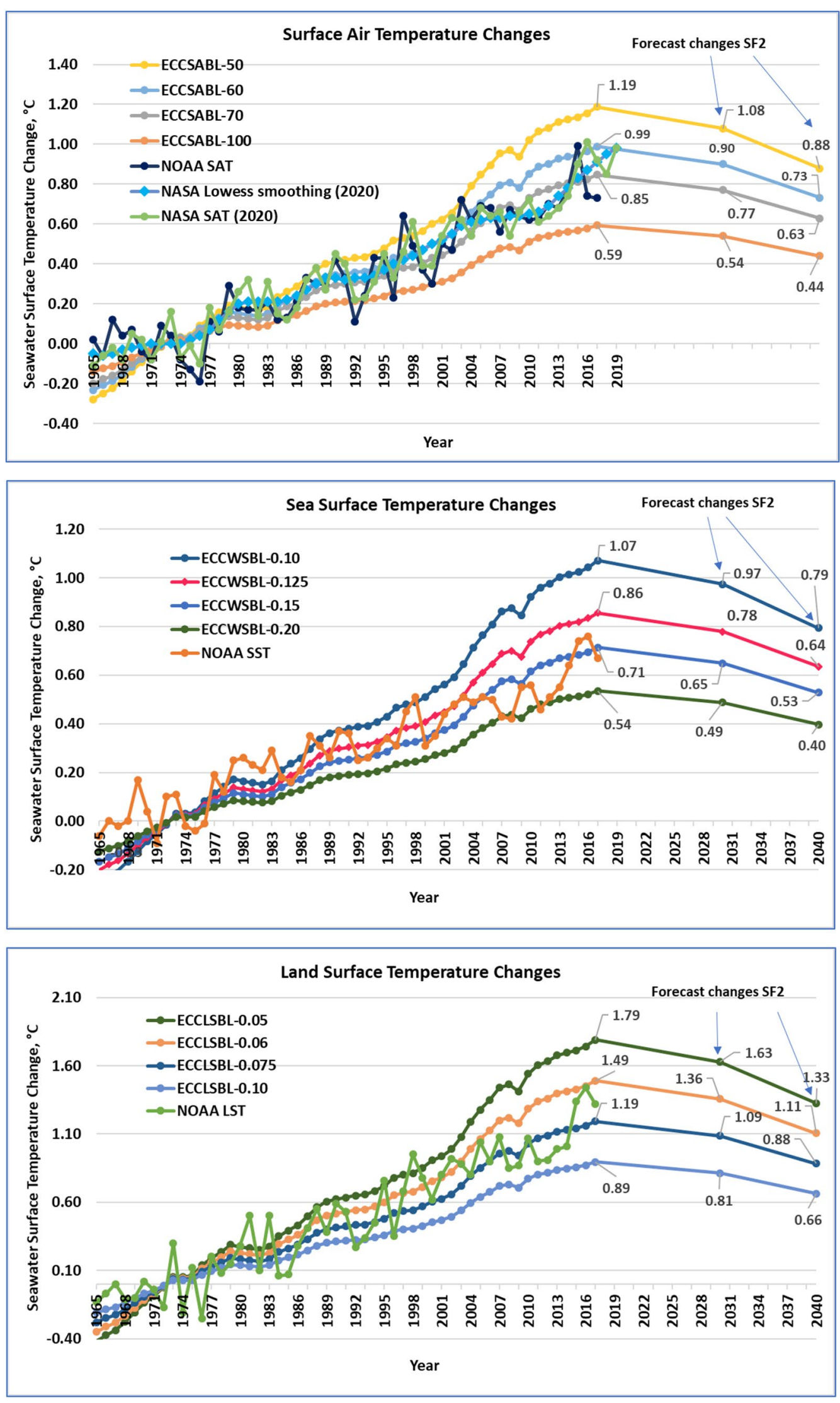
anomalies and the temperature changes in land surface layer with a depth between 0.05 (recently 0.06 ) and $0.10 \mathrm{~m}$ are consistent with the land temperature anomalies. The air temperature changes at the air layer depth of $70 \mathrm{~m}$ are almost the same as NASA's Lowess Smoothing trend.

Knowing the dominating root cause can provide the right path and meaningful approaches for the battle. Efforts in merely pursuing GHG reductions are bound to be ineffective and inefficient but increase burdens. We can no longer afford to waste any precious time, efforts and resources, and must properly adjust our strategies and policies effectively. International scientific communities should pay more attentions on the residual heat or waste heat and investigate further how it impacts the local and global climate patterns etc., and policymakers should consider how to switch the efforts and resources from focusing on GHG reduction to waste heat reduction efficiently by developing effective policies.

Besides, ice interacts with the air, oceans and land and ice melting influences the global warming by absorbing vast amount of heat. However, assuming a constant melting rate during a long term is evidently inappropriate (especially at early time), it affects the accurate simulation of past temperature changes. Therefore, collecting ice melting data in details such as the melt quantity, the temperature at which the ice existed/exists, is of significance to better understand the global warming and climate change.

It is forecast that under the business as usual scenario, possible warmings in air will be $0.68 \sim 1.13^{\circ} \mathrm{C}$ in 2030 , $0.73 \sim 1.22{ }^{\circ} \mathrm{C}$ in 2040 ; in oceans $0.61 \sim 0.98{ }^{\circ} \mathrm{C}$ in 2030 , $0.66 \sim 1.05{ }^{\circ} \mathrm{C}$ in 2040 ; in land $1.02 \sim 1.71{ }^{\circ} \mathrm{C}$ in 2030 and $1.10 \sim 1.84^{\circ} \mathrm{C}$ in 2040 , respectively.

Improving energy's conversion efficiency would substantially suppress the warming. Under the elevated energy conversion efficiency scenario, the possible warmings in air would be $0.54 \sim 0.90{ }^{\circ} \mathrm{C}$ in $2030,0.44 \sim 0.73{ }^{\circ} \mathrm{C}$ in 2040; in oceans $0.49 \sim 0.78{ }^{\circ} \mathrm{C}$ in $2030,0.40 \sim 0.64{ }^{\circ} \mathrm{C}$ in 2040; in land $0.81 \sim 1.36{ }^{\circ} \mathrm{C}$ in $2030,0.66 \sim 1.11^{\circ} \mathrm{C}$ in 2040 , respectively.

In order to effectively slow down or stop the further warming, here are three strategic approaches recommended:

1. Developing surface renewable energies such as solar, wind, hydro and ocean energies will be most effective; switching to $100 \%$ of surface renewable energies is the most ideal solution and can completely stop further warming (because they are within the earth's energy budget balance); Prudentially planned use of biomass is advisable (concentratedly burning massive biomass in a short time may break the in-situ energy budget balance); Pursuing low carbon fuel is helpful to some extent (due to blending partly biomass); Using geotherm, a kind of renewable energy, will accelerate the global warming from the perspective of energy budget balance. All these will certainly promote the advancements and applications of new technologies in these surface renewable energies.

2. Reducing energy consumption and saving energy will directly reduce the heat amount entering the environment through retrofit (of existing technologies and processes) and individual and social behavior changes. This is the easiest, most cost-effective and practical solution. Eliminating flaring will contribute greatly to mitigating the current climate change, helping conserve resources. Education plays a very important role in this aspect.

3. Increasing the global energy's total effective conversion efficiency or simply the energy conversion efficiency will efficiently mitigate the warming and climate change. This is the most important but difficult task and will largest challenge the technology and industrial sectors and need great deal of investments too. It may embrace new technology breakthroughs and great changes in production processes.

It is anticipated that after implementing these strategies both in technologies and processes, human's lifestyle will be dramatically changed. Energy applications will be more efficient and cleaner. Human's reliance on fossil fuels will shift onto surface renewable energies, while traditional resources development and applications will be limited.

\section{Abbreviations}

GHG: Greenhouse gas; Lowess Smoothing: Locally weighted scatterplot smoothing; ECCM: Equivalent climate change model; ECCSABL-x: Equivalent climate change surface air boundary layer at depth of $x$ meters, $x=50,60,70$, $100, \ldots$ meters; ECCWSBL-x: Equivalent climate change waters surface boundary layer at depth of $x$ meters, $x=0.1,0.125,0.15,0.2 \ldots$ meters; $E C C L S B L-x$ : Equivalent climate change land surface boundary layer at depth of $x$ meters, $x=0.05,0.06,0.075,0.10 \ldots$ meters; GETECE: Global energy's total effective conversion efficiency; SF1: Business as usual scenario regarding to the GEECE, i.e. $\mathrm{GEECE}=20 \%$; SF2: Elevated energy conversion efficiency scenario, i.e. GEECE increased by $10 \%$ by 2030 and increased another $10 \%$ by 2040 ; NASALST: NASA's land surface temperature anomalies; NASA-SAT: NASA's surface air temperature anomalies; NASA-SST: NASA's sea surface temperature anomalies.

\section{Acknowledgements}

The author is grateful to his family for their unconditional support for this research project conducted independently at home at his spare time.

\section{Authors' contributions}

The author is responsible for all aspects of composing the paper. All authors read and approved the final manuscript.

\section{Funding}

Not applicable. 
Availability of data and materials

The data used to analyse and support this paper is available.

\section{Ethics approval and consent to participate}

Not applicable.

\section{Consent for publication}

This is an independent personal research project conducted at home at the author's spare time, the author is willing to publish it to share with the international scientific communities and the policymakers.

\section{Competing interests}

As mentioned above, it's a personal independent research, no any external funding. Thus, there is no any conflicts with any body, any organizations or institutions.

Received: 12 March 2020 Accepted: 30 April 2020

Published online: 10 May 2020

\section{References}

Bian Q (2019) The nature of climate change-equivalent climate change model's application in decoding the root cause of global warming. Inter J Env Climate Change. 9(12):801-822. https://doi.org/10.9734/ijecc/2019/ v9i1230160

BP. P.I.c. BP Energy Outlook, 2019 Edition, 2019. https://www.bp.com/en/globa l/corporate/energy-economics/energy-outlook/energy-outlook-downl oads.html

Flanner MG (2009) Integrating anthropogenic heat flux with global climate models. Geophys Res Lett 36:L02801. https://doi.org/10.1029/2008G L036465

Flato G, Marotzke J, Abiodun B, Braconnot P, Chou SC, Collins W, Cox P, Driouech F, Emori S, Eyring V, Forest C, Gleckler E, Guilyardi C, Jakob V Kattsov C. Reason and M. Rummukainen, 2013: Evaluation of Climate Models. In: Climate Change 2013: The Physical Science Basis (Figure 9.8).
Contribution of Working Group I to the Fifth Assessment Report of the Intergovernmental Panel on Climate Change [Stocker TF, D Qin, G-K. Plattner, M Tignor, SK. Allen, J Boschung, A Nauels, Y Xia, V Bex and PM Midgley (eds.)]. Cambridge University Press, Cambridge, United Kingdom and New York

IPCC, 2014: Climate change 2014: Synthesis Report. Contribution of Working Groups I, II and III to the Fifth Assessment Report of the Intergovernmental Panel on Climate Change [Core Writing Team, R.K. Pachauri and L.A. Meyer (eds.)]. IPCC, Geneva, Switzerland, pp 151 https://epic.awi.de/id/ eprint/37530/1/IPCC_AR5_SYR_Final.pdf

IPCC fourth assessment report: climate change 2007, working group I: the physical science basis, executive summary, https://archive.ipcc.ch/publi cations_and_data/ar4/wg1/en/ch2s2-es.html

Murray J, Heggie D (2016) From urban to national heat island: the effect of anthropogenic heat output on climate change in high population industrial countries. Earth Future. https://doi.org/10.1002/2016EF000352

National Aeronautics and Space Administration, GISS Surface Temperature Analysis (v4), https://data.giss.nasa.gov/gistemp/graphs_v4/, Accessed 11 April 2020

Skeptical Science, It's Waste Heat. https://skepticalscience.net/pdf/rebuttal/ waste-heat-global-warming-intermediate.pdf, Accessed 6 April 2020

United Nations, Climate Change, https://www.un.org/en/sections/issue s-depth/climate-change/ Accessed 4 Feb 2020

Skeptical Science, What does past climate change tell us about global warming?. https://skepticalscience.com/climate-change-little-ice-age-medie val-warm-period-intermediate.htm. Accessed 7 Feb 2020

\section{Publisher's Note}

Springer Nature remains neutral with regard to jurisdictional claims in published maps and institutional affiliations.

\section{Submit your manuscript to a SpringerOpen ${ }^{\circ}$ journal and benefit from:}

- Convenient online submission

- Rigorous peer review

- Open access: articles freely available online

- High visibility within the field

- Retaining the copyright to your article

Submit your next manuscript at $\boldsymbol{\nabla}$ springeropen.com 